\title{
A PROMOÇÃO DA SAÚDE MENTAL E SUA INFLUÊNCIA NAS RELAÇÕES INTERPESSOAIS DE IDOSOS INSTITUCIONALIZADOS: UM RELATO DE EXPERIÊNCIA EM PSICOLOGIA SOCIAL COMUNITÁRIA ${ }^{1}$
}

\author{
Maisa Bastos Nunes² \\ Faculdade Integral Diferencial - Facid Wyden \\ Milene Martins ${ }^{3}$ \\ Universidade Federal do Piauí - UFPI
}

\section{RESUMO}

No contexto do envelhecimento populacional, em que a tendência é que o número de idosos aumente cada vez mais quando comparado com as outras faixas etárias, surgem questões como as condições de cuidados que esses idosos receberão. Esses cuidados, antes função das famílias, na contemporaneidade, com as suas reorganizações, passa a ser função também do Estado e do mercado privado, surgindo assim alternativas como as Instituições de Longa Permanência para Idosos (ILPIs), tanto públicas quanto privadas, locais em podem atuar diversos profissionais, entre eles, o psicólogo. A partir da experiência de um estágio obrigatório do curso de Psicologia, na área da Psicologia social comunitária, foi construído este relato de experiência que tem como foco a promoção da saúde mental e as relações interpessoais. Problematizou-se a seguinte questão: Como a promoção da saúde mental influencia as relações interpessoais de idosos institucionalizados? Foi elaborado como objetivo geral para esse trabalho: Analisar como a promoção da saúde mental pode contribuir para a melhoria das relações interpessoais de idosos de uma ILPI. E como objetivos específicos: Descrever as relações construídas entre os idosos, apresentar as práticas de promoção da saúde mental realizadas e descrever os desafios do campo de estágio em psicologia social comunitária. Para isso, foram realizadas atividades em três eixos: atividade lúdica, estimulação dos processos mentais e rodas de conversa, cujos registros foram realizados por meio do diário de campo. No decorrer das atividades, foi verificado que cada idoso criou, no seu processo de isolamento, estratégias para se proteger do abandono, com tendência ao silêncio, pouca interação entre os pares, contribuindo para as perdas dos processos mentais, como memória, linguagem e percepção. A partir das atividades realizadas, pôde-se perceber que a promoção da saúde mental pode contribuir positivamente para as relações interpessoais dos idosos, à medida que estimula a aproximação do grupo, a expressão das emoções, o reconhecimento entre os membros, o fortalecimento de laços e etc. Revelou-se que uma das dificuldades para a melhoria das relações é a prática do isolamento e exclusão pelos próprios sujeitos. Assim, as atividades realizadas, além de estimular processos mentais, contribuíram para o rompimento desse ciclo, convidando os sujeitos a interagirem, o que possibilitou a participação constante dos idosos, a estimulação da comunicação entre eles, o resgate das memórias afetivas através de músicas, histórias de vida e situações do passado, proporcionando a eles um sentimento de identidade e igualdade.

Palavras-Chave: Saúde Mental. Relação Interpessoal. Idosos.

\footnotetext{
${ }^{1}$ Trabalho apresentado no Congresso Brasileiro Ciência e Sociedade (CBCS 2019), promovido pelo Centro Universitário Santo Agostinho, de 03 a 05 de outubro de 2019, em Teresina-PI.

${ }^{2}$ Aluna do $10^{\circ}$ período do curso de Psicologia da Facid Wyden. Email: isabastos23@gmail.com

${ }^{3}$ Mestre em Educação pela Universidade Federal do Piauí. Professora da Universidade Federal do Piauí, Floriano-PI.

Email: martinsmilene@ig.com.br

ISBN: 978-65-80968-11-4 DOI: $10.17648 /$ cbcs-2019-110634
} 
ANAIS CBCS 2019 | 3 a 5 de outubro de 2019 | Centro Universitário Santo Agostinho - Teresina - PI

\section{ABSTRACT}

In the context of population aging, where the tendency is for the number of older people to increase more and more when compared to other age groups, questions arise as to the conditions of care that these elderly will receive. This care, previously a function of families, nowadays, with their reorganization, becomes also a function of the State and the private market, thus creating alternatives such as the Public and Private LongTerm Care Institutions for the Elderly. Several professionals can act, including the psychologist. From the experience of a compulsory internship of the Psychology course, in the area of community social psychology, this experience report was built that focuses on the promotion of mental health and interpersonal relationships. The question was: How does the promotion of mental health influence the interpersonal relationships of institutionalized elderly? It was elaborated as general objective for this work: To analyze how the promotion of mental health can contribute to the improvement of the interpersonal relations of the elderly of an LSIE. And as specific objectives: Describe the relationships built between the elderly, present the practices of mental health promotion performed and describe the challenges of the internship field in community social psychology. For this, activities were performed in three axes: playful activity, stimulation of mental processes and conversation wheels, whose records were made through the field diary. During the activities, it was found that each elderly created, in their isolation process, strategies to protect themselves from abandonment, with a tendency to silence, little interaction between peers, contributing to the loss of mental processes such as memory, language and perception. . From the activities performed, it could be seen that the promotion of mental health can contribute positively to the interpersonal relationships of the elderly, as it stimulates the approach of the group, the expression of emotions, the recognition among the members, the strengthening of ties. and etc. It turned out that one of the difficulties in improving relationships is the practice of isolation and exclusion by the subjects themselves. Thus, the activities performed, besides stimulating mental processes, contributed to the breaking of this cycle, inviting the subjects to interact, which enabled the constant participation of the elderly, the stimulation of communication between them, the rescue of affective memories through music, past life stories and situations, giving them a sense of identity and equality.

Key-words: Mental Health. Interpersonal Relationship. Elderly.

\section{INTRODUÇÃO}

No contexto do envelhecimento populacional, em que a tendência é que o número de idosos aumente cada vez mais quando comparado com as outras faixas etárias, surgem questões como as condições de cuidados que esses idosos receberão. Esses cuidados, antes função das famílias, na contemporaneidade, com as suas reorganizações, passa a ser função também do Estado e do mercado privado, surgindo assim alternativas como as Instituições de Longa Permanência para Idosos (ILPIs), tanto públicas quanto privadas, tema ainda pouco pesquisado no Brasil (CAMARANO; KANSO, 2010). 
ANAIS CBCS 2019 | 3 a 5 de outubro de 2019 | Centro Universitário Santo Agostinho - Teresina - PI

Apesar de não haver um consenso sobre o conceito de ILPI, sua origem remonta aos asilos para a população carente resultantes da caridade cristã frente à falta de políticas públicas. No Brasil, 65,2\% dessas instituições são filantrópicas. De forma geral, entende-se por ILPIs residências coletivas que atendem pessoas com 60 anos ou mais, que necessitem de cuidados diários, independentemente de sua renda ou da renda de sua família, possuindo ou não suporte familiar, sejam instituições governamentais ou não-governamentais, em situação de liberdade, dignidade e cidadania (CAMARANO; KANSO, 2010).

Os idosos institucionalizados ou não, possuem alguns indicadores para avaliar o bem-estar e qualidade de vida, como longevidade, relações de amigos e familiares, produtividade, entre outros. O envelhecimento não está sendo descrito como questão de doença, mas como um processo que faz parte do ciclo de vida. Dessa forma, a saúde do idoso está relacionada com a autonomia, a independência, o bem-estar e a qualidade de vida (LIMA; LIMA; RIBEIRO, 2010). No Brasil, o envelhecimento populacional acarreta uma grande procura por serviços e instituições que cuidem e deem atenção diária para os idosos. Contudo, o processo de envelhecimento pode acarretar alterações na saúde mental do idoso e a institucionalização pode desencadear um agravamento dos processos cognitivos, na qualidade de vida e na saúde mental dos idosos (TRINDADE et al., 2013).

Durante esse processo de institucionalização o idoso passa por um período de adaptação, muitos perdem o contato com a família ou já não o tinham no momento que adentraram na instituição. Mesmo recebendo assistência médica, moradia, alimentação e demais cuidados diários, estes têm uma grande necessidade afetiva, de diálogo, de serem tratados com respeito e escutados, o que abre espaço para a atuação da Psicologia (CARVALHO; DIAS, 2011), que no caso desta pesquisa, foi realizado dentro da proposta do estágio obrigatório do curso.

Ao realizar este relato de experiência, problematizou-se a seguinte questão: Como a promoção da saúde mental influencia as relações interpessoais de idosos institucionalizados? Foi elaborado como objetivo geral para esse trabalho: Analisar como a promoção da saúde mental pode contribuir para a melhoria das relações interpessoais de idosos de uma ILPI. E como objetivos 
ANAIS CBCS 2019 | 3 a 5 de outubro de 2019 | Centro Universitário Santo Agostinho - Teresina - P

específicos: Descrever as relações construídas entre os idosos, apresentar as práticas de promoção da saúde mental realizadas e descrever os desafios do campo de estágio em psicologia social comunitária.

O interesse pela realização deste relato surgiu primeiramente como sugestão de Trabalho de Conclusão de Disciplina, o qual, com a orientação da supervisora de estágio, foi elaborado para que pudesse ser publicado, visto que as atividades realizadas foram experiências ricas em conhecimento, aliando teoria e prática, de maneira a contribuir para o crescimento acadêmico e profissional das estagiárias. Sua temática mostrou-se relevante para ampliar a visão social acerca da realidade de idosos institucionalizados, compartilhar as vivências destes, assim como atentar para a necessidade de serem ouvidos. Enquanto relato, esta pesquisa pode contribuir para que outros estudantes e/ou profissionais interessem-se por este campo, em um viés da Psicologia Social Comunitária, contribuindo para a construção dos fazeres e saberes do psicólogo.

\section{METODOLOGIA}

O estágio foi realizado por três alunas do sétimo bloco do curso de Psicologia, no período compreendido entre março e junho de 2018. Inicialmente, foi realizada a visita ao local, juntamente com a professora supervisora, estabelecido o dia e horário. Durante o período do estágio, o grupo realizou práticas com os idosos englobando três eixos: atividade lúdica, estimulação dos processos mentais e rodas de conversa. Como a psicóloga do local era voluntária, o plano de ação foi debatido com a coordenadora da instituição e com a supervisora acadêmica do estágio. Além disso, a instituição oportunizou um certo grau de autonomia para as estagiárias, o que contribuiu para seus crescimentos profissionais e individuais.

O estágio foi realizado numa Instituição de Longa Permanência para Idosos de Teresina-PI, que atende 35 idosos carentes, sendo 18 homens e 17 mulheres, com idades entre 66 a 101 anos, que recebem 1 salário mínimo de aposentadoria. Sua equipe conta com 34 funcionários: a diretorapresidente, a vice-diretora, o secretário, a coordenadora, cuidadores, auxiliares de escritório, 
ANAIS CBCS 2019 | 3 a 5 de outubro de 2019 | Centro Universitário Santo Agostinho - Teresina - P

técnicos de enfermagem e funcionários dos serviços gerais, cozinha e lavanderia. Possui ainda o apoio de voluntários da área de saúde, como: fonoaudiólogo, nutricionista, clínico geral, psicóloga, psiquiatra, assistente social, ortopedista, angiologista e cardiologista. A instituição apresenta uma estrutura física construída para atender a demanda da clientela assistida, com quartos masculinos e femininos, salas de refeição, espaço ao ar livre e salas para atividades, além dos espaços para administração, limpeza, lavanderia e cozinha.

Assim, esta pesquisa consiste em um relato de experiência, que segundo Prodanov e Freitas (2013) resulta de uma reflexão embasada em uma experiência vivenciada e em seu aparato teórico, em forma de relato. Como forma de registro das atividades propostas, foi utilizado um diário de campo. Segundo Soares et al. (2011), este é um instrumento de anotações, reflexões e análise de tudo que se vivenciou no dia a dia do estágio, para uso individual. Ele facilita a criação do hábito de escrever, compartilhando suas experiências e refletindo acerca da sua vivência, além de ser útil para recordar tudo que coletou. A partir destes registros, os resultados obtidos foram comparados e embasados utilizando-se produções científicas, tais como artigos e livros.

\section{RESULTADOS E DISCUSSÃO}

Essa seção contém o relato do ocorrido na execução de cada uma das atividades, assim como a descrição de algumas falas dos participantes e as impressões pessoais das estagiárias envolvidas, retiradas de seus diários de campo. Para preservar suas identidades os nomes dos participantes foram substituídos pelo nome de cores e para fins de sistematização esses relatos foram separados em subtópicos, que serão apresentados a seguir.

Distribuindo as atividades entre os eixos trabalhados encontram-se: atividade lúdica (Teatro Interativo), estimulação dos processos mentais (Sarau Musical e Objetos de Época, Troca de Mensagens e Jogo de Trilha), rodas de conversa (Dois momentos).

\section{Atividade lúdica}


ANAIS CBCS 2019 | 3 a 5 de outubro de 2019 | Centro Universitário Santo Agostinho - Teresina - PI

O Teatro Interativo teve como objetivo integrar mais o grupo utilizando-se a ludicidade, por meio da criação de uma história em tempo real. Para isso, foram utilizados 2 fantoches, sendo um masculino e outro feminino, uma mala contendo objetos aleatórios, como um martelo, um abacaxi de porcelana, um livro, entre outros. Os idosos foram dispostos em um círculo e lhes foi dada a orientação de que criariam uma história juntos, a partir dos objetos presentes.

Começou-se com os fantoches, um menino e uma menina, batizados pelos participantes de Francisco Barbosa e Conceição Ambrosina. Com os objetos da mala obteve-se o seguinte roteiro: Conceição Ambrosina era uma menina levada, que havia quebrado o "abacaxi de porcelana" da mãe. O pai, Francisco Barbosa, iria bater na menina com um "martelo", mas a mãe não deixou. Eles foram para a igreja, pedir perdão a Deus (cruz). Ambrosina ia a escola, onde lia e estudava (livro). Ela foi crescendo, se casou e aos 40 anos tinha 50 filhos (Helena, Rita, Ana, Laura, Isaura, Pedro, Joaquim, Antônio, Francisco, Chico Tunda Maneu de Azebaijir, e etc.). Seu marido era carpinteiro, trabalhava o dia todo e Ambrosina e as filhas se revezavam levando comida para ele e na cozinha.

Em seguida, o sr. Azul Claro foi contando uma história de um delegado que gostava de brigar nas festas. Então, foram contadas 3 histórias do livro "volta ao mundo em 52 histórias" de Philip (2012), a saber: "João preguiçoso"; “Grilo, o adivinho" e "Mentira!”. Percebeu-se questões como a posição da mulher na família, a forma de criação que eles conheciam, a religiosidade, as famílias numerosas e a forma como eles retratavam na história criada suas próprias vivências, o que está em consonância com os resultados de Marin et al. (2012), que ao estudarem as histórias de vida de idosos institucionalizados, perceberam um contexto socioeconômico desfavorecido.

A escolha de uma atividade lúdica baseou-se na ideia de que esta estratégia favorece a interação social, estimula relatos pessoais, constrói um vínculo e empatia entre os participantes, que identificam na história contada pela outra pessoa semelhanças com a sua, contribuindo para a promoção da saúde mental (CYRINO et al., 2016). Além disso, através de sua realização, pôde-se ter acesso às representações sociais dos idosos sobre família, o papel da mulher e o casamento. Essas representações referem-se aos saberes populares e do senso comum, elaborados e partilhados coletivamente, com a finalidade de construir e interpretar o real (MOSCOVICl, 2015). 
ANAIS CBCS 2019 | 3 a 5 de outubro de 2019 | Centro Universitário Santo Agostinho - Teresina - P

\section{Estimulação dos processos mentais}

As atividades descritas abaixo tiveram como objetivo estimular os processos mentais, como memória, atenção, percepção, linguagem e emoção. Estes processos não são divisíveis, mas sim sistemas complexos que envolvem zonas cerebrais, que por sua vez contribuem para a formação de processos psicológicos complexos (FUENTES et al., 2013).

O Sarau Musical e Objetos de Época teve o objetivo de trabalhar a memória e a linguagem, de forma a contribuir para a interação grupal. Foi pedido que os idosos contassem para o grupo as memórias que tinham ao ouvir as músicas e ver fotos de objetos de sua época. Foi possível observar a dificuldade do grupo em começar, até que o sr. Branco falou do tempo que pescava piaba perto de casa usando arroz como isca, já o sr. Marrom contou que "comecei a trabalhar com 13 anos, aquele negócio de adolescência eu não tive, fui trabalhar, fui motorista, trabalhei em firmas, passei em concurso, cheguei a ir e voltar mais de 60 vezes, ia de avião e voltava de carro levando gente", falou dos tipos de carro que dirigiu, dos que conheceu e do problema de visão que o deixou cego.

A sra. Laranja disse "eu canto para não chorar, não me calo, eu gosto de falar, sou brincalhona, gosto de sorrir". O sr. Azul Escuro disse que veio para Teresina aos 12 anos e começou a trabalhar em um banco aos 18. A sra. Amarela estava com a fala bastante comprometida, enquanto a sra. Bege falava coisas aleatórias e gesticulava. A sra. Creme contou a uma das estagiárias que foi doméstica, não saia para festas, gostava de trabalhar e fazia vários doces; ela estava na instituição devido aos maus tratos da família, mas mesmo assim sentia falta deles, pois nunca mais havia recebido visitas, por isso era quieta e calada. Como os idosos falavam em tom de voz baixo, era necessário repassar as histórias ao restante do grupo, exceto a da sra. Creme, por decisão da estagiária e da idosa.

Uma voluntária do local, sra. Rosa, começou a cantar com os idosos, que bateram palmas, movimentaram os braços, o sr. Vermelho até levantou para dançar com uma estagiária. Foi um momento de descontração, desabafo e partilha, que auxiliou no combate ao fator isolamento 
ANAIS CBCS 2019 | 3 a 5 de outubro de 2019 | Centro Universitário Santo Agostinho - Teresina - PI

descrito por Martins (2006), alcançando assim seu objetivo por meio do compartilhamento de histórias de vida e a criação de um momento propício para a interação.

A Troca de Mensagens teve como objetivo facilitar a expressão e compartilhamento da emoção através da escrita. Nessa atividade, muitos idosos não sabiam o que dizer para escrever. A sra. Turquesa se recusou a dizer uma mensagem, mesmo tendo participado da atividade anterior. O sr. Violeta precisou que a tarefa fosse explicada 3 vezes, chegando a perguntar se havia algum problema em dizer que gostava de si mesmo e dos outros, ao que foi respondido que não havia problema algum nisso. No momento do sorteio das mensagens entre eles, o sr. Violeta não quis ficar com a mensagem do sr. Azul Escuro, por atritos passados, então a mensagem foi trocada sem que o restante do grupo percebesse, para evitar um novo atrito. Assim, foi possível observar a dificuldade deles em verbalizar sentimentos para os outros, a existência de atritos entre o grupo, mas também foi positivo no sentido de incentivá-los a interagir.

Percebe-se em idosos institucionalizados a pouca interação e apoio social, que geralmente é fornecida mais por amigos do que por familiares, uma vez que as instituições se preocupam em fornecer ajuda física e material e não conseguem suprir, por si só, a necessidade afetiva dos idosos. Assim, teoriza-se que a dificuldade de verbalização dos sentimentos deva-se aos fatores mencionados anteriormente (RODRIGUES; SILVA, 2013).

A atividade Jogo da Trilha teve como objetivo estimular a atenção e o trabalho em equipe. Os times homens versus mulheres disputaram no jogo de trilha, revezando a jogada do dado entre seus membros. Os participantes demonstraram seu espírito competitivo e as mulheres ganharam de 2 a 0 . Os homens desistiram de continuar devido ao placar, mas todos se envolveram na atividade, mostrando que conseguem trabalhar em equipe, apesar das suas limitações.

\section{Rodas de conversa}

A primeira Roda de Conversa foi realizada devido à morte do sr. Vermelho, com os senhores, para que falassem sobre a interação entre eles, como se sentiam e suas opiniões sobre o local. De 
ANAIS CBCS 2019 | 3 a 5 de outubro de 2019 | Centro Universitário Santo Agostinho - Teresina - P

modo geral, eles confirmaram a existência de intrigas, sendo que o sr. Azul Escuro falou dos idosos que haviam falecido desde sua chegada no local. O sr. Marrom falou que "só falo com as pessoas se falarem comigo, com pessoa que tem cultura. [...] Eu estou bem, só não estou melhor porque o meu amigo Vermelho se foi. Eu dava conselho pra ele, conselho não, parecer. Mas foi melhor morrer aqui do que na rua, ele já estava sofrendo mesmo". O sr. Branco contou que não conversa muito com os colegas, pois eles são distantes e ele não divide quarto com ninguém.

Nesse mesmo dia, o grupo de estagiárias ficou sabendo que o sr. Vermelho era quem dava o ombro para o sr. Marrom, que é cego, ajudando-o no caminho. Pôde-se discutir com a psicóloga do local, a sra. Vinho, a forma como eles costumavam atribuir ao outro um defeito, apontando-o, mas nunca vendo o seu e conformando-se em ficar cada um no seu espaço, com raras exceções.

Diante disso, evidencia-se que os idosos institucionalizados reproduzem práticas de isolamento e exclusão entre si mesmos, afastando-se e dificultando ainda mais a interação grupal, o que, em última instância, pode contribuir para o declínio da saúde mental destes. Apesar da inciativa das estagiárias e da psicóloga, percebe-se a necessidade de mudanças internas nos indivíduos envolvidos, para que estes não venham a desenvolver, por exemplo, a depressão, que aumenta de $14 \%$ (em idosos não institucionalizados) para $30 \%$ de chance em indivíduos nesta condição (FRADE et al., 2015).

Na segunda Roda de Conversa, a psicóloga voluntária, sra. Vinho, discorreu sobre o conceito de relação interpessoal, como sendo a forma como uma pessoa se relaciona com a outra, percebendo as especificidades de cada um e compreendendo-as ao se relacionar com o outro (FORMOZO et al., 2012). Falou sobre a importância do respeito ao outro, a interdependência entre as pessoas e as formas de interação. Então foi realizada a primeira dinâmica, criada pelo grupo de estagiárias, em que se interpretava uma discussão sem emitir som, ao final da qual cada uma se dirigia para um canto, irritada com a outra, para que então se revelasse que, de forma mais dramatizada, aquela era o tipo de interação que era vista entre eles, em que alguns discutiam, possuíam atritos e no fim cada um ficava no seu canto. $\mathrm{O}$ sr. Marrom colaborou para discussão confirmando que percebia essa situação e os demais se puseram a refletir. 
ANAIS CBCS 2019 | 3 a 5 de outubro de 2019 | Centro Universitário Santo Agostinho - Teresina - PI

A seguir, foi solicitado que cada um relatasse o que aprendeu um com outro, completando a frase "com seu Fulano eu aprendi que...". Essa segunda dinâmica fez com que eles se sentissem mais valorizados no grupo, sendo citados como aprendizado: o respeito, a amizade, o tratamento para com os outros e até a rezar. O sr. Marrom e um dos funcionários presentes foram os mais citados. No encerramento, pediu-se que eles praticassem mais o diálogo, mesmo quando as estagiárias não estivessem mais no local.

Foi o dia em que mais interagiram e participaram, em que se sentiram ouvidos pelos colegas e tiveram um espaço para falar. Percebeu-se o potencial da dinâmica de grupo enquanto conjunto de técnicas, que propicia aos participantes trabalharem suas dificuldades (AUBRY; SAINT-ARNAUD, 2010). Em sua realização, uma das estagiárias assumiu o papel de facilitadora, mediando o grupo durante o reconhecimento de sua realidade e acompanhando o ritmo deste (FAILDE, 2014).

\section{CONSIDERAÇÕES FINAIS}

A maioria dos idosos tinha dificuldades para andar, precisavam ficar sentados, tinham a fala, a visão e outras funções comprometidas. Outros quase não reagiam aos estímulos ou estavam acamados. Muitos se sentiam abandonados por suas famílias, não viam seus parentes há anos ou décadas, o que se reflete na falta de interação entre eles, tema que foi bastante trabalhado no período de estágio. Foi verificado que cada idoso criou, no seu processo de isolamento, estratégias para se proteger do abandono, com tendência ao silêncio, pouca interação entre os pares, contribuindo para as perdas dos processos mentais, como memória, linguagem e percepção.

Estes fatos da realidade dos idosos reforçam o processo de exclusão social e o agravamento da saúde mental, pois o abandono dos familiares e o isolamento social contribuem para que o idoso acabe perdendo o contato com a realidade pessoal e coletiva, o que contribui para o aumento da chance de desenvolver depressão ou outros quadros psicopatológicos, além de acelerar o declínio cognitivo (FRADE et al., 2015; TRINDADE et al., 2013).

A partir das atividades realizadas, pôde-se perceber que a promoção da saúde mental pode contribuir positivamente para as relações interpessoais dos idosos, à medida que estimula a 
ANAIS CBCS 2019 | 3 a 5 de outubro de 2019 | Centro Universitário Santo Agostinho - Teresina - PI

aproximação do grupo, a expressão das emoções, o reconhecimento entre os membros, o fortalecimento de laços e etc.

Revelou-se que uma das dificuldades para a melhoria das relações é a prática do isolamento e exclusão pelos próprios sujeitos, que, no caso relatado, atribuíam aos outros defeitos que não conseguiam ver em si mesmos, pouco dialogavam e careciam de iniciativa para o diálogo. Assim, as atividades realizadas, além de estimular processos mentais, contribuíram para o rompimento desse ciclo, convidando os sujeitos a interagirem.

Assim, entre os desafios deste campo de estágio em psicologia social comunitária pode-se citar: a disposição dos sujeitos para a participação das atividades, visto que nem sempre o estado de saúde contribui para tal; os declínios cognitivos e de funções como a fala; o rompimento de práticas de isolamento e exclusão; e a presença diária de profissionais de Psicologia, de forma a suprir as demandas encontradas.

Desta forma, pôde-se concluir que o estágio foi de suma de importância e aprendizado, à medida que se conheceu a prática do psicólogo no campo, vendo seus limites e desafios. Foi uma oportunidade para aprender a manejar o sofrimento do outro em casas de longa permanência, para o aprimoramento profissional diante das demandas identificadas, para que se pudesse abordar assuntos que muitas vezes são estigmatizados pela instituição ou a sociedade. Percebeu-se que ao longo do estágio se criaram diversos vínculos e estabeleceu-se uma colaboração proveitosa para ambas as partes, sendo por isso de suma importância para a construção dos saberes e fazeres em Psicologia.

\section{REFERÊNCIAS}

AUBRY, Jean-Marie; SAINT-ARNAUD, Yves. Dinâmica de grupo: iniciação a seu espírito e algumas de suas técnicas. 6. ed. São Paulo: Edições Loyola, 2010.

CAMARANO, Ana Amélia; KANSO, Solange. As instituições de longa permanência para idosos no Brasil. Revista brasileira de estudos de população, São Paulo, v. 27, n. 1, p. 232-235, 2010.

CARVALHO, Maria Paula Rodrigues Sequeira de; DIAS, Maria Olívia. Adaptação dos idosos institucionalizados. Millenium, [s. I.], v. 40, n. 1, p. 161-184, 2011. 
ANAIS CBCS 2019 | 3 a 5 de outubro de 2019 | Centro Universitário Santo Agostinho - Teresina - P

CYRINO, Renata Souza et al. Atividades lúdicas como estratégia de educação em saúde com idosos. Revista Ciência em Extensão, [s. I.], v. 12, n. 3, p. 154-163, 2016.

FAILDE, Izabel. Manual do facilitador para dinâmicas de grupo. Campinas: Papirus Editora, 2014.

FORMOZO, Gláucia Alexandre et al. As relações interpessoais no cuidado em saúde: uma aproximação ao problema. Revista Enfermagem UERJ, Rio de Janeiro, v. 20, n. 1, p. 124-127, 2012.

FRADE, João et al. Depressão no idoso: sintomas em indivíduos institucionalizados e nãoinstitucionalizados. Revista de Enfermagem Referência, Coimbra, n. 4, p. 41-49, 2015.

FUENTES, Daniel et al. Neuropsicologia: teoria e prática. 2. ed. Rio de Janeiro: Artmed, 2013.

LIMA, Deusdedit Lima; LIMA, Maria Alice Vieira Damaceno; RIBEIRO, Cristiane Galvão. Envelhecimento e qualidade de vida de idosos institucionalizados. Revista Brasileira de Ciências do Envelhecimento Humano, [s. I.], v. 7, n. 3, 2010.

MARIN, Maria José Sanches et al. Compreendendo a história de vida de idosos institucionalizados. Revista brasileira de geriatria e gerontologia, [s. I.], v. 15, n. 1, p. 147-154, 2012.

MARTINS, Rosa Maria. Envelhecimento e políticas sociais. Millenium, [s. I.], p. 126-140, 2006.

MOSCOVICl, Serge. Representações sociais: investigações em psicologia social. 11. ed. Rio de Janeiro: Vozes, 2015.

PHILIP, Neil. Volta ao mundo em 52 histórias. 2. ed. São Paulo: Companhia das Letrinhas, 2012.

PRODANOV, Cleber Cristiano; FREITAS, Ernani Cesar de. Metodologia do trabalho científico. Novo Hamburgo: Feevale, 2013.

RODRIGUES, Adriana Guimarães; SILVA, Ailton Amélio da. A rede social e os tipos de apoio recebidos por idosos institucionalizados. Revista brasileira de Geriatria e Gerontologia, Rio de Janeiro, v. 16, n. 1, p. 159-170, 2013.

SOARES, Amanda Nathale et al. O diário de campo utilizado como estratégia de ensino e instrumento de análise do trabalho da enfermagem. Revista Eletrônica de Enfermagem, [s. I.], v. 13, n. 4, p. 665-70, 2011.

TRINDADE, Ana Paula Nassif Tondato da et al. Repercussão do declínio cognitivo na capacidade funcional em idosos institucionalizados e não institucionalizados. Fisioterapia em Movimento, Curitiba, v. 26, n. 2, p. 281-289, 2013. 